\title{
Adult drinking in Australian schools
}

\author{
Geoffrey Munro, ${ }^{1}$ Penny Buykx, ${ }^{2}$ Bernadette Ward, ${ }^{2}$ Julie Rae, ${ }^{1}$ John Wiggers ${ }^{3}$ \\ 1. Australian Drug Foundation, Victoria \\ 2. Centre of Research Excellence in Rural and Remote Primary Health Care, School of Rural Health, Monash \\ University, Victoria \\ 3. School of Medicine and Public Health, University of Newcastle, New South Wales
}

n 2011, the Australian National Council on Drugs (ANCD) suggested that the use, sale or promotion of alcohol for the purpose of fundraising by schools was not consistent with education values or ethical principles. ${ }^{1,2}$ It argued that fundraising with alcohol offended the 'whole school approach to health' as it normalised alcohol for school students and could lead to underage people adopting a positive attitude toward early drinking. A precedent exists: many schools have removed soft drinks and 'non-nutritious' foodstuffs from their canteen in order to align school practice with the school health curriculum. ${ }^{1}$ In particular, the ANCD objected to students playing any role in alcohol-related transactions, such as carrying offers of alcohol via school newsletters or delivering payments to the school. ${ }^{1,2}$

Nevertheless, alcohol has a clear presence in schools in Australian government, independent and Catholic education systems. Apprehension at its influence reaches beyond fundraising and extends to the consumption of alcohol at school events and functions in the presence of children. Concern over this issue is evident in the broader community. A newspaper account in Victoria in mid-2012 of complaints the Australian Drug Foundation (ADF) had received about drinking by adults at school events triggered a further 65 media items, including interviews with stakeholders, reports and comments in radio, television and newspapers across the country. ${ }^{3,4}$ Media attention continued in 2013 when teachers at primary and secondary schools in Melbourne reported 'drunken parents' had assaulted a staff member at a school activity and disrupted a valedictory function such that a school banned alcohol at all future events. ${ }^{5}$ Further attention to problematic effects of such drinking was called by the Public Schools Association (PSA) of Western Australia in 2013 when, following instances of 'raucous behaviour', the Association banned drinking by spectators at school sporting events. The PSA explained that drinking by parents while watching school sport 'was not conducive to role-modelling for boys' and 'could become more of a problem if we allowed it to continue.6 Following the initial publicity, on seven occasions between September 2012 and mid-2013, parents confidentially informed the Australian Drug Foundation (ADF) of their opposition to the consumption of alcohol by adults at school functions, particularly when students were present. Schools nominated by those parents included government and Catholic primary schools and Catholic secondary schools in suburban Melbourne and country Victoria.

Despite public qualms about the place of alcohol in schools across Australia, changes to liquor licensing legislation by the state government in Queensland in 2013 may facilitate drinking within schools. As part of a campaign against bureaucratic 'red tape,' the government abolished the legal requirement for schools to apply for and gain a permit in order to sell alcohol for fundraising purposes. ${ }^{\text {? }}$ For the Queensland government it appears that there is no issue of propriety in a school promoting, drinking or selling alcohol. These different perspectives raise several questions. What role does alcohol play in Australian schools? Under what circumstances is alcohol consumed within the school setting or jurisdiction? What policy issues are related to such consumption? What guidance do schools have in navigating those issues? Is it appropriate that alcohol is consumed in the presence of students at school events?

Alcohol is used in Australian schools for three broad and overlapping purposes: to generate revenue; for ritualised or celebratory purposes, and recreational usage, each of which is summarised below.

\section{Generating revenue}

1. Alcohol is sold to adults for immediate consumption at school fairs, fetes and other events at which children are present.

2. Alcohol is sold to adults or raffled or bottled under the jurisdiction of the school for consumption at a future time. These events need not involve children although in some cases they may be present or otherwise participate in the process.

3. Alcohol is supplied or sold by the school to adults at fundraising events, such as Trivia Nights, at which children are not present.

\section{Ritual/celebration}

4. Alcohol is served at meetings of school councils, which are usually adult-only events.

5. Alcohol is served at valedictory dinners attended by staff, students and parents where students may drink alcohol because they fulfil one of two conditions: they are of legal age (18 years) or they are in the company of a parent who can give consent to their underage child being served alcohol.

\section{Recreational}

6. Alcohol is supplied or sold to adults by the school at children's events such as student discos, art shows, plays and performances.

7. Parents bring a personal supply of alcohol (BYO) to consume at a school event or function, such as a sports day.

8. Teachers drink alcohol in the staff room after work.

9. Teachers drink alcohol on school camps after children are bedded down.

At state and territory level, the attitude of education departments and governments regarding the use of alcohol by adults appears to differ markedly.

In New South Wales (NSW) drinking is not permitted at any school function when school students are present. ${ }^{8}$ Drinking by staff and parents is permitted under various circumstances in all other jurisdictions.

In Queensland, liquor licensing regulations allow alcohol to be sold and consumed by adults on school premises for fundraising purposes though the document is silent on the matter of student attendance. ${ }^{9}$ In Victoria, the Australian Capital Territory, the Northern Territory, South Australia and Tasmania, 
drinking by staff is not permitted whenever they are responsible for students. Policy in Victoria allows drinking by staff at school functions when students are not present and at school functions on licensed premises when underage students are supervised by a parent. ${ }^{10}$ In Tasmania and the Northern Territory, drinking is prohibited at 'student focussed events' but is permitted at other events; similarly, in Western Australia, South Australia and the Australian Capital Territory, drinking by parents and staff at social and fundraising events is acceptable. ${ }^{11-15}$

Departmental policy in most jurisdictions refers to the need for schools to meet regulatory obligations (e.g. liquor licensing, responsible service of alcohol) or to heed 'community standards' or 'harm minimisation principles'. Victoria does not allow students to be involved in alcohol-related fundraising while South Australia requires principals to consider whether such activity is consistent with its health promotion program.

Thus, there is no consensus across Australian jurisdictions regarding the use of alcohol within schools. Alcohol-related fundraising is allowed in some but not all jurisdictions. Drinking is either prohibited completely, or permitted when students are not present, or permitted in the presence of students when students are the responsibility of their parent. The ambiguity is underlined by the need for interpretation of an event at which a child's presence is tangential. Children are central to a student art show, performance or play, sports event and disco; at some schools children have a designated role in preparing for and attending fetes and fairs, although their presence may not be essential. The rule that teachers cannot drink when they are 'responsible for students' may create confusion when some, but not all, parents attend a graduation dinner: Is the staff responsible for the student who is not accompanied by a parent? Is it sufficient for one staff member to remain abstinent on that occasion while other staff members imbibe, or should all staff abstain?

With the exception of NSW, official attitudes conflict with the stance of the ANCD and parent critics are concerned at the association of alcohol, and the modelling of drinking by teachers and parents within the education process. Instead, most departmental perspectives view drinking through the prism of a legal duty of care and adherence to the licensing laws and regulations which apply in each jurisdiction. In Victoria, for example, a community organisation that sells alcohol in a public setting is required to hold a limited liquor licence and to have one person who is certified in the responsible service of alcohol on duty at the serving station, which is delimited by a 'red line' area around the station. Anecdotal reports given to the ADF of service from a mobile trolley at a school fete may offend the conditions of the limited licence and leave the school liable to a financial penalty. Overall, the degree to which schools that sell or serve alcohol comply with state or territory licensing laws and regulations is unknown.

The capability for school staff or volunteers to control the level of drinking by patrons at school functions, especially if an intervention is required to limit or end an individual's access to alcohol, is also unknown. As professional bar staff can fail to identify persons who are intoxicated, or to cease serving them, it is likely that community members may be less inclined or less able to act in that situation. ${ }^{16}$ The presence of BYO alcohol at school functions may exacerbate the risk of uncontrolled drinking and adverse outcomes, as has already been reported. ${ }^{5}$ Related to this is a concern that children's safety, wellbeing, or enjoyment of the occasion may be threatened by the behaviour of a person who is affected by alcohol.

The core issue, according to the parents who communicated with the ADF, is that drinking at school in the presence of children provides an adverse model for them because it creates the norm that drinking is part of all social activity. They believe it undermines the school's health teaching that adolescents should defer drinking, a view that is supported by the current Australian drinking guidelines that recommend young people avoid alcohol until the age of $18 .{ }^{17}$ One primary school parent, whose school variously sold alcohol at the fete, raffled cases of beer and sold bottled wine decorated with a photo of the school, said: "Alcohol has its place, but surely it is not on school grounds or at school events where children are present". ${ }^{18} \mathrm{~A}$ secondary school parent was concerned that the school gave alcohol undue prominence because it served alcohol at parent information nights, at parents and friends meetings, and at the Year 12 dinner, which was attended by underage students. ${ }^{19}$ Another source alleged that parental drinking diverted attention from the children who were the nominal focus of an event: She testified that at a 'fun sports night' she was the only parent who helped with the event "...as all the other mums and dads where (sic) busy drinking. Not one of the mums or dads came down to the kids to say great work or well done".20

Three of the sources had referred their complaint about the use of alcohol at school events that were attended by students to the school principal or the school council. In each case none was satisfied. One source, from a country town, said she had been warned not to make a fuss because fewer parents might attend school functions if they could not drink at them. She was told her child might suffer if she maintained her complaint. ${ }^{21} \mathrm{~A}$ source whose child attended a primary school in the city stated the school council had rejected her complaint once and she worried about being labelled a 'wowser' if she raised the matter again. ${ }^{21}$ In another case, when a source had told a school council that adults need to lead by example and show young people that drinking is not essential for having fun, its members expressed 'surprise and exasperation. ${ }^{\prime 8}$ Council members had replied that the school's use of alcohol was 'responsible' and it might be instructive for students to see adults drinking moderately. ${ }^{18}$ Such concerns demonstrate a need for clarity and transparency regarding school decisionmaking. How well equipped and informed are school principals and councils to make such decisions? What support is available to support that decision-making?

Quantitative evidence on the extent and effect of school-based drinking is unavailable as empirical investigations have not been conducted. However, the critics (including parents and teachers) believe drinking in schools is poor modelling because it gives primacy to alcohol and suggests that drinking is appropriate and must be accommodated in all settings and all times. It is analogous to the case put forward by the ANCD that called on schools "to [avoid] using children and young people under the age of 18 in any way to promote alcohol" in their fundraising activities because it could contradict "the school's policy and education" messages about alcohol. ${ }^{2}$ Apprehension that school drinking will be damaging is supported by the anecdotal accounts from school personnel, across different states, of uncontrolled and excessive drinking by parents and guests at school functions. Identified harms to date include the disruption of children's activities and events at schools; public modelling of hazardous 
and harmful levels of drinking; violent assault; children's embarrassment and shame as a result of parental behaviour; and sharp division within school communities. ${ }^{3,5,6,18-21}$

The ANCD's hope that schools might contribute to "changing the culture associated with alcohol'"resonates with a common national policy aspiration. ${ }^{1}$ The National Alcohol Strategy (NAS) notes that alcohol is "normalised into everyday Australian consumer behaviour" and that "habits, customs, images and norms" contribute to the central location of alcohol in Australian social life. ${ }^{22}$ The aims of the NAS include "facilitating safer and healthier drinking cultures" and the National Preventative Health Task Force (NPHT) aims to "reshape the drinking culture".22,23 However, as Roche has pointed out, 'drinking culture' is not defined and, as a result, the contour of the desirable drinking culture is unclear. ${ }^{24}$ While the NAS suggested a reassessment of what is socially acceptable in relation to the consumption of alcohol is required, both it and the NPHT's strategy focus attention on reducing risky drinking and intoxication, rather than on the 'time and place' of drinking. That might be an effect of the national policy of harm minimisation which has directed attention to the outcomes of drug use rather than on the act of consumption. ${ }^{25}$ If reducing the prevalence, incidence or depth of intoxication among drinkers qualifies as 'cultural change' there may be no need to quarantine some places and times as 'off-limits' for drinking. By contrast, for the ANCD, 'cultural change' will include redrawing boundaries around alcohol use so that in some locations and times it will have no place.

Among the state and territory governments, only NSW adopts the strictest position of 'no alcohol in school'. Of the nine examples of the use of alcohol by schools that are enumerated above, the ANCD prohibition on alcohol related fundraising would rule out schools from selling or serving alcohol in the first three cases. A midway position that is implicit in the view of the complainants to the ADF would allow alcohol to be consumed by adults at school functions when students are not present, and for fundraising projects when students are not involved in the process. That would allow the use of alcohol at school council meetings (case 4 ) at some fundraising events (case 3 ) and at staff-only events (case 8). The compromise position would prevent consumption at valedictory dinners (case 5), at child-centric events such as art shows, plays and discos (cases 6 and 7) and on school camps and trips (case 9).

It is clear from the responses to the complaints reported by the informants that efforts to remove alcohol from some schools will be contested. Whether key stakeholders (school administrators, teachers, parents) agree to stop selling, serving and drinking alcohol in the presence of children may be an indicator of whether the cultural change that policymakers believe is necessary to reduce alcohol related harm is achievable. .2,23 $^{2}$

Although he excoriated male drinking rituals in his analysis of mid-20th century Australia, Donald Horne doubted his homeland was 'an alcoholic society' because drinking was not essential to every social occasion:'a man might get as full as a boot at the pub but he would not touch a drop of it in his own home.26 The demand to drink at school events underlines how Australian drinking customs have changed and social boundaries around alcohol use have dissolved in the decades since The Lucky Country. Drinking at schools might represent perfectly the'normalisation of alcohol into everyday Australian consumer behaviour'22 Nevertheless, school principals and schools councils might be advised to develop transparent policies on all matters related to the use of alcohol after comprehensive consultation with all parents and other stakeholders in their community. To rely on the school council as an expression of parental views may not be sufficient.

The varied nature of the views of national, state, and territory policymakers, and the diversity of opinion among teachers and parents, indicates the promotion and use of alcohol in Australian schools is a divisive issue. It is a matter that appears to be growing in public awareness and concern. Yet the extent of drinking at school functions is unknown and further investigation is required to ascertain its purpose, prevalence, impact, and outcome. Similarly, it is unclear how school authorities make their decisions when they consider the place of alcohol in their school. Empirical research is needed to determine the prevalence of alcohol use by adults in school settings and the degree to which this may or may not be an emerging public health problem for principals, school councils and school communities.

\section{Acknowledgements}

The authors thank Katrin Hausdorf and two anonymous reviewers for their helpful advice. The first author was supported by a grant from the Department of Health, Victoria, to the Community Alcohol Action Network, ADF.

\section{References}

1. Australian National Council on Drugs. School Fundraising and Alcohol [Internet]. Canberra (AUST): ANCD; 2011 [cited 2013 Aug 5]. Available from: http://www.ancd.org.au/Publications-and-Reports/ publications.htm

2. Australian National Council on Drugs. School Fundraising and Alcohol: An Open Letter to all School Principals [Internet]. Canberra (AUST): ANCD; 2011 [cited 2013 Aug 5]. Available from: http://www.ancd. org.au/Publications-and-Reports/publications.html

3. Stark J, Browne R. Keep booze out of schools, parents told. The Sunday Age. 2012: September 23.

4. Australian Drug Foundation. Supporting Australians to Live Healthier Lives. Annual Review 2013. Melbourne (AUST): ADF; 2013. Unpublished observations.

5. Critchley C. A beer in there. Sunday Herald Sun. 2013: August 4.

6. Hiatt B, King R. Alcohol ban at school sports, The West Australian. 2013; February 18.

7. Moore T. Schools can soon serve alcohol without a permit. Brisbane Times. 2013; March 17.

8. Education and Communities. Drugs in School Policy [Internet]. Sydney (AUST): State Government of New South Wales; 2010 [cited 2013 Aug 5]. Available from: https://www.det.nsw.edu.au/policies/student_serv/ student welfare/drug incid/PD20020040.shtml

9. Office of the Queensland Parliamentary Counsel. Liquor and Gaming (Red Tape Reduction) and Other Legislation Amendment Bill 2013 [Internet]. Brisbane (AUST): State Government of Queensland; 2013 [cited 2013 Oct 14]. Available from: https://www.legislation.qld.gov.au/ Bills/54PDF/2013/LiquorGamingRedTapeAmB13E.pdf

10. Department of Education and Early Childhood Development School Policy and Advisory Guide - Policy and Advice for Schools [Internet]. Melbourne (AUST): State Government of Victoria; 2012 [cited 2013 Aug 5]. Available from: http://www.education.vic.gov.au/ school/principals/spag/Pages/spag.aspx

11. Department of Education. Alcohol-Schools [Internet] Hobart (AUST): State Government of Tasmania; 2012 [cited 2013 Aug 5]. Available from: https://www. education.tas.gov.au/documentcentre/Documents/ Alcohol-School-Guidelines.pdf

12. Department of Education and Training. Alcohol Consumption on DET Premises [Internet]. Darwin (AUST): Government of the Northern Territory; 2010 [cited 2013 Aug 5]. Available from: http://www. education.nt.gov.au/ data/assets/pdf file/0004/598/ AlcoholConsumption.pdf

13. Department of Education. Alcohol on School Premises [Internet]. Perth (AUST): State Government of Western Australia; 2011 [cited 2013 Aug 5]. Available from: http://det.wa.edu.au/policies/detcms/policy-planningand-accountability/policies-framework/policies/ alcohol-on-school-premises.en?oid=au.edu.wa.det. cms.contenttypes.Policy-id-11822279

14. Department of Education and Children's Services Intervention Matters [Internet]. Adelaide (AUST): State Government of South Australia; 2011 [cited 2013Aug 5]. http://www.decd.sa.gov.au/drugstrategy/files/ links/2590_DECS_IM_book_2_WEB.pdf

15. Workplace and Legal Support. Alcohol - Possession and Consumption in Schools and At School Related Activities [Internet]. Canberra (AUST): Australian Capital Territory Education Youth and Family Services; 1998 [cited 2013 Aug 5]. Available from: http://www.det.act. gov.au/_data/assets/pdf_file/0009/17595/Alcoholposession-and-consumption-in-schools-and-schoolrelated-activities.pdf 


\section{Commentary}

16. Saltz RF. What is evidence and how can we provide it? In:Stockwell T, Gruenewald PJ,Toumbourou JW, Loxley W.editors. Preventing HarmfulSubstance Use. Chichester (UK): John Wiley and Sons; 2005. p. 313-24.

17. National Health and Medical Research Council. Australian Guidelinesto Reduce Health Risksfrom Drinking Alcohol [Internet]. Canberra (AUST): Commonwealth of Australia; 2009 [cited 2013 Aug 5]. Available from: http://www.nhmrc.gov.au/_files_nhmrc/publications/ attachments/ds10-alcohol.pdf

18. Private communication to first author, 19/9/2012. Unpublished observations.

19. Private communication to first author, 19/9/2012. Unpublished observations.

20. Private communication to first author, 04/04/2012. Unpublished observations.

21. Private communication to first author, 13/05/2013. Unpublished observations.

22. Ministerial Council on Drug Strategy. National Alcohol Strategy 2006-2011 Towards Safer Drinking Cultures [Internet]. Canberra: (AUST): Commonwealth Department of Health; 2006 [cited 2013 Aug 5]. Available from: http://www.health.gov.au/internet/ alcohol/publishing.nsf/Content/nas-06-09

23. National Preventative Health Taskforce. Australia: The Healthiest Country by 2020. National Preventative Health Strategy - the Roadmap for Action [Internet]. Canberra (AUST): Commonwealth of Australia; 2009 [cited 2013 Aug 5]. Available from: http://www.health.gov.au/ internet/preventativehealth/publishing.nsf/Content/ A06C2FCF439ECDA1CA2574DD0081E40C/\$File/ discussion-28oct.pdf

24. Roche A, Bywood P, Freeman T, et al. The Social Context of Alcohol Use in Australia. Adelaide (AUST): National Centre for Education and Training on Addiction; 2009.

25. Munro G, Ramsden R. Primary prevention: Preventing the uptake of drugs. In: Ritter A, Hamilton M, King T, editors.Drug Usein Australian Society. South Melbourne (AUST): Oxford University Press; 2013. p. 135-68.

26. Horne D. The Lucky Country. Ringwood (AUST): Penguin Books; 1976.

Correspondence to: Mr Geoffrey Munro, Australian Drug Foundation, PO Box 818, North Melbourne, Victoria 3051;

e-mail: munro@adf.org.au 